\title{
PENINGKATAN KEMAMPUAN MENULIS LAPORAN DENGAN MODEL PEMBELAJARAN BERBASIS PORTOFOLIO
}

\author{
Ratna Juita \\ Guru MTS Negeri 2 Kota Bengkulu \\ ratnajuita1967@gmail.com
}

Submit, 02-09-2018 Accepted, 06-12-2018 Publish, 10-12-2018

\begin{abstract}
ABSTRAK
Penelitian ini bertujuan untuk (1) mendeskripsikan hasil pembelajaran menulis laporan sebelum dilakukan model pembelajaran berbasis portofolio siswa kelas VIII B MTs Negeri 2 Bengkulu, (2) mendeskripsikan hasil model pembelajaran menulis laporan setelah dilakukan pembelajaran berbasis portofolio siswa kelas VIII B MTs Negeri 2 Bengkulu, (3) mendeskripsikan peningkatan kemampuan menulis laporan berbasis model pembelajaran portofolio siswa kelas VIII B MTs Negeri 2 Bengkulu.(1) Penelitian adalah penelitian tindakan, dengan teknik analisis deskriptif. Hasil penelitian ini adalah Rata-rata nilai hasil pre tes materi pelajaran menulis laporan adalah 64 pada kategori cukup dan persentse ketuntan klasikal $75 \%$. (2) Rata-rata nilai hasil diskusi siswa materi pelajaran menulis laporan dengan model pembelajaran portofolio pada siklus I adalah 74 dengan kategori sedang. (3) Rata-rata hasil diskusi siswa materi pelajaran menulis laporan dengan model pembelajaran portofolio pada siklus II adalah 80 kategori baik. (4) Rata-rata hasil pos tes materi pelajaran menulis laporan dengan model pembelajaran portofolio adalah 80 dengan kategori baik. (5) Persentase ketuntasan klasikal $100 \%$ tuntas pada siklus II. (6) Model pembelajaran berbasis portofolio cukup akurat untuk dilaksanakan dalam meningkatkan hasil belajar siswa. Simpulan penelitian ini adalah model pembelajaran berbasis portofolio cukup akurat untuk dilaksanakan dalam meningkatkan hasil belajar siswa
\end{abstract}

Kata Kunci: Kemampuan Menulis Laporan, Model Pembelajaran Berbasis Portofolio

\section{ABSTRACT}

This study aimed to (1) describe the learning outcome of writing a report before a portfolio-based learning model of the students of class VIII B at MTs Negeri 2 Bengkulu was conducted, (2) describe the result of the learning model in writing a report after portfolio-based learning in class VIII B MTs Negeri 2 Bengkulu was conducted, (3) describe the improvement in the ability to write a report based on the portfolio-based learning model of the students of class VIII B at MTs Negeri 2 Bengkulu. (1) The research was an action research, with descriptive analysis technique. The results of this study were the mean of the result of the pre-test in writing report material was 64 in sufficient category and the percentage of classical mastery was 75\%. (2) The mean score of the students' discussion result on writing report subject with the portfoliobased learning model in the first cycle was 74 in medium category. (3) The mean score of students' discussion result on writing report subject with the portfolio-based learning model in cycle II was 80 in good category. (4) The mean result of the post-test on 
writing report material with the portfolio-based learning model was 80 in good category. (5) The percentage of classical mastery was $100 \%$ achived in cycle II. (6) The portfolio-based learning model was accurate enough to be implemented in improving student learning outcome. The conclusion of this study was that the portfolio-based learning model was accurate enough to be implemented in improving student learning outcome.

Key word: The Ability to Write a Report, Portfolio-Based Learning Model

\section{PENDAHULUAN}

Salah satu bentuk inovasi pengajaran yang dapat dilakukan oleh guru dalam proses pembelajaran adalah model pembelajaran berbasis portofolio. Model pembelajaran berbasis portofolio dapat dikatakan sebagai upaya mendekatkan siswa kepada objek yang dibahas. Pengajaran yang menjadikan materi pelajaran yang dibahas secara lansung dihadapkan kepada siswa atau siswa secara langsung mencari informasi tentang hal yang dibahas ke alam atau masyarakat sekitar (Fajar, 2002). Model pembelajaran portofolio disamping memperoleh pengalaman fisik terhadap objek alam pembelajaran, siswa juga memperoleh pengalaman atau terlibat mental. Pengalaman fisik berarti melibatkan atau mempertemukan siswa dengan objek pembelajaran. Lebih lanjut Fajar (2002) menjelaskan bahwa dengan pembelajaran portofolio siswa mendapat pengalaman mental dalam arti memperhatikan informasi awal yang telah ada pada diri siswa, dan memberikan kebebasan kepada siswa untuk menyusun (merekonkruksi) sendiri-sendiri informasi yang diperolehya.

Model pembelajaran potofolio dapat memberikan keragaman sumber belajar, dan memberikan keleluasan kepada siswa untuk memilih sumber belajar yang sesuai pada masing masing siswa. Hal ini sesuai dengan salah satu prinsip dalam pengembangan kurikulum yaitu pembelajaran yang berpusat pada siswa sebagai pembangun pengetahuan, dalam upaya untuk memandirikan peserta didik untuk belajar, berkolaborasi, membantu teman, mengadakan pengamatan dan penilaian diri untuk suatu refleksi dan mendorong mereka membangun pengetahuannya sendiri.

Upaya peningkatan pembelajaran menulis laporan melalui pembelajaran berbasis portofolio, dilakukan karena pembelajaran berbasis portofolio adalah pembelajaran yang berorientasi pada proses pelibatan peserta didik secara intensif dalam pembelajaran. Melalui model pembelajaran ini siswa akan terlibat dalam seluruh rangkaian proses pembelajaran, mulai persiapan, pelaksanaan, sampai dengan evaluasi. 
Pembelajaran model ini menggunakan prinsip dasar pembelajaran siswa aktif, kelompok belajar kooperatif, dan pembelajaran partisipatorik (Budimansyah, 2003). Dengan demikian, jika model pembelajaran berbasis portofolio ini diterapkan dalam pembelajaran menulis laporan, maka siswa akan secara aktif terlibat, bekerja sama, dan berpartisipasi dalam kegiatan menulis laporan. Dengan demikian, siswa memiliki sejumlah pengalaman praktis menulis laporan yang cukup memadai, bukan hanya sekedar teori menulis laporan.

Model pembelajaran dalam penelitian ini berbasis portofolio merupakan bentuk interaksi belajar mengajar yang dirancang untuk membantu peserta didik agar dapat memahami teori secara mendalam melalui pengalaman belajar praktik-empirik (Budimansyah, 2003). Hal ini merupakan perubahan pola pikir kegiatan belajar mengajar yang berfokus pada guru menuju kegiatan belajar mengajar yang berfokus pada siswa. Model pembelajaran ini dapat mendorong terbentuknya kompetensi peserta didik secara utuh karena selain siswa diharapkan menguasai domain teoritis, siswa dituntut memahami masalah yang terkait, mencari alternatif pemecahan, serta merencanakan tindakan nyata. Dengan demikian, model pembelajaran ini akan memadukan secara sinergis antara aspek kognitif, afektif, dan psikomotorik (Somantri, dalam Fajar, 2003).

Kehidupan sehari-hari siswa selalu mengadakan komunikasi, baik komunikasi satu arah meupun komunikasi dua arah. Komunikasi satu arah misalnya mendengarkan siaran radio, mendengarkan siaran televisi, menulis. Sedangkan komunikasi dua arah misalnya interaksi antara dokter dengan pasien, antara guru dengan guru, antara guru dengan siswa, dan antara siswa dengan siswa. Menulis merupakan salah satu kemampuan berbahasa. Kemampuan menulis sangat penting untuk semua orang menulis mecerminkan tingkat berbahasa seseorang. Menulis laporan merupakan salah satu ragam tulisan ekspositori dan tulisan ekspositori merupakan genre dari ragam tulisan secara umum, uraian kajian teoritis menulis laporan diawali dengan penyajian konsep dasar menulis, proses menulis, dan ragam menulis. 


\section{METODE PENELITIAN}

Penelitian yang akan diterapkan adalah penelitian tindakan kelas. Menurut Kunandar (2013), penelitian tindakan kelas adalah sebuah bentuk kegiatan refleksi diri yang dilakukan oleh para pelaku pendidikan dalam suatu situasi kependidikan untuk memperbaiki rasionalitas dan keadilan. Sedangkan menurut Arikunto (2014), mendefinisikan penilaian tindakan kelas adalah suatu pencermantan terhadap kegiatan belajar berupa sebuah tindakan, yang sengaja dimunculkan dan terjadi dalam sebuah kelas secara bersamaan. Penelitian tindakan ini diharapkan mampu meningkatkan hasil menulis siswa dengan penggunaan model pembelajaran berbasis portofolio. Penelitian tindakan kelas ini melibatkan guru mata pelajaran yang berperan sebagai rekan dalam mendiskusikan tindakan, sedangkan peneliti berperan sebagai pengamat dan partisifan. Instrumen pengumpul data yang digunakan dalam penelitian ini ada dua jenis yaitu: (1) Lembar observasi, (2) Tes menulis laporan (mengarang). Teknik analisis data yang digunakan dalam penelitian ini adalah teknik analisis deskriptif. Teknik ini digunakan untuk mendeskripsikan peningkatan kemampuan menulis laporan pembelajaran berbasis portofolio siswa kelas VIIIB MTS Negeri 2 Kota Bengkulu Tahun Pelajaran 2017/2018.

\section{HASIL PENELITIAN}

Hasil pre tes yang dilakukan sebelum pembelajaran dilaksanakan adalah sebagai berikut;

Tabel 1

Hasil Pre Tes

\begin{tabular}{lll}
\hline No & \multicolumn{1}{c}{ Keterangan } & Jumlah \\
\hline 1 & Jumlah siswa & 37 orang \\
\hline 2 & Jumlah siswa yang tuntas belajar & 27 orang \\
\hline 3 & Jumlah siswa yang belum tuntas belajar & 10 Orang \\
\hline 4 & Nilai rata-rata & 63,83 \\
\hline 5 & Ketuntasan belajar klasikal & $75 \%$ \\
\hline
\end{tabular}

Berdasarkan hasil diskusi kelompok yang telah dilaksanakan pada siklus I didapat nilai hasil diskusi sebagai berikut: 
Tabel 2

Hasil Diskusi Siklus I

\begin{tabular}{lll}
\hline No & \multicolumn{1}{c}{ Kelompok } & Nilai \\
\hline 1 & Kelompok 1 & 72 \\
\hline 2 & Kelompok 2 & 67 \\
\hline 3 & Kelompok 3 & 75 \\
\hline 4 & Kelompok 4 & 74 \\
\hline 5 & Kelompok 5 & 80 \\
\hline 6 & Kelompok 6 & 77 \\
\hline 7 & Kelompok 7 & 70 \\
\hline & Rata-rata & 73,57 \\
\hline & Ketuntasan belajar klasikal Kategori & Sedang \\
\hline
\end{tabular}

Berdasarkan hasil diskusi kelompok yang telah dilaksanakan pada siklus II didapat nilai hasil diskusi sebagai berikut:

Tabel 3

Hasil Diskusi Siklus II

\begin{tabular}{|c|c|c|}
\hline No & Kelompok & Nilai \\
\hline 1 & Kelompok 1 & 78 \\
\hline 2 & Kelompok 2 & 81 \\
\hline 3 & Kelompok 3 & 78 \\
\hline 4 & Kelompok 4 & 84 \\
\hline 5 & Kelompok 5 & 81 \\
\hline 6 & Kelompok 6 & 76 \\
\hline 7 & Kelompok 7 & 83 \\
\hline 8 & Kelompok 8 & 77 \\
\hline 9 & Kelompok 9 & 79 \\
\hline & Rata-rata & 79,66 \\
\hline & Ketuntasan belajar klasikal Kategori & Baik \\
\hline
\end{tabular}

Hasil evaluasi yang berupa pos tes yang dilakukan setalah pembelajaran siklus dua dilaksanakan adalah sebagai berikut

Tabel 4.

Hasil Pos Tes

\begin{tabular}{lll}
\hline No & \multicolumn{1}{c}{ Keterangan } & Jumlah \\
\hline 1 & Jumlah siswa & 37 orang \\
\hline 2 & Jumlah siswa yang tuntas belajar & 37 \\
\hline 3 & Jumlah siswa yang belum tuntas belajar & - \\
\hline 4 & Nilai rata-rata & 79,62 \\
\hline 5 & Ketuntasan belajar klasikal & $100 \%$ \\
\hline
\end{tabular}




\section{PEMBAHASAN}

Pembelajaran menulis yang biasa dilakukan oleh guru mata pelajaran selama ini menggunakan metode ceramah, tanya jawab dan penugasan. Penerapan metode ini ternyata tidak mampu meningkatkan kemampuan menulis siswa secara baik. Hal ini dari hasil pre tes yang dilakukan dan berdasarkan hasil studi pendahuluan peneliti. Siswa pada waktu mengikuti pelajaran nunjukan respon yang kurang, siswa pasif hanya mendengarkan dan melaksanakan tugas seadanya.

Berdasarkan kenyataan di atas, maka peneliti mencoba berklaborasi dengan guru mata pelajaran yang meruapakan sejawat peneliti untuk merancang dan menerapkan pendekatan yang baru yaitu model pembelajaran berbasis portofolio, dengan harapan kemampuan menulis siswa dapat meningkat.

\section{Hasil Belajar Siswa Sebelum Menerapkan Model Pembelajaran Berbasis Portofolio}

Sebelum melakukan tindakan dengan pengegunaan model pembelajaran berbasis portofolio, terlebih dahulu melaksankan pre tes, untuk mengetahui kemampuan awal siswa. Hasil pre tes tersebut adalah sebagai berikut (1) jumlah siswa kelas VIII/B adalah 37 orang, (2) jumlah siswa yang tuntas belajar sebanyak 27 orang, (3) jumlah siswa yang belum tuntans belajar sebanyak 10 orang, (4) nilai rata-rata 63,83 dibulatkan menjadi 64, (5) ketuntasan belajar klasikal $75 \%$.

Dari hasil pre tes di atas kelihatan bahwa masih banyak siswa yang belum tuntas belajar dari 37 orang siswa kelas VIII/B ternyata masih 10 orang masih belum tuntas belajar. Dan nilai rata-rata kelas 64 masih dalam kategori sedang belum mencapai kategori baik apalagi kategori sangat baik masih jauh sekali. Persentase ketuntasan belajar klasikal masih di bawah ketentuan sekolah, dimana ketentuan sekolah adalah $\geq$ $85 \%$ baru dikategorikan tuntas, sedangkan hasil pre tes baru mencapai $75 \%$.

\section{Hasil Belajar Siswa Setelah Menerapkan Model Pembelajaran Berbasis Portofolio}

Setelah menerapkan model pembelajaran berbasis portofolio suasana belajar sudah sangat aktif, antuasime siswa sangat tinggi, kondisi pembelajaran kondusif dan guru dapat menguasi kelas dengan baik. Hal ini ditandai dengan tanggapan-tangan siswa dalam diskusi baik diskusi kelompok maupun diskusi kelas. 
Hasil belajar siswa setelah menggunakan model pemebalajaran berbasis portofolio semakin meningkat rata-rata nilai hasil diskusi siswa pada siklus I 73,57 dibulatkan menjadi 74 dengan kategori sedang, meningkat pada siklus II menjadi 79, 66 dengan kategori baik. Rata-rata hasil pre tes 64 meningakat menjadi rata-rata hasil pos tes 79,66 dibulatkan menjadi 80 . Artinya ada peningkatan sebesar $17,5 \%$. Persentase ketuntasan klasikal juga meningkat, dari hasil pre tes hanya $75 \%$ yang tuntas menjadi $100 \%$ tuntas pada siklus II

\section{Peningkatan Hasil Belajar Siswa Setelah Merapkan Model Pembelajaran Berbasis Portofolio}

Dari hasil penelitian di atas jelas bahwa terdapat peningkatan kemampuan menulis laporan siswa dengan menggunakan model pembelajaran berbasis portofolio yang signifikan, hal ini dibuktikan dari peningkatan hasil pos tes dan hasil prosentase peningkatan ketuntasan klasikal. Hasil penelitian ini sejalan dengan hasil penelitian Tukiran (2008) yang menjelaskan bahwa model pembelajaran berbasis portofolio lebih baik, lebih efektif dan lebih produktif dibandingkan dengan model pembelajaran konvensional, Penelitian Zuhri (2008) menjelaskan pembelajaran dengan model portofolio ini dapat meningkatkan aktifitas guru, siswa, proses pembelajaran serta respon kepedulian siswa terhadap lingkungan, Mujianto (2008) mejelaskan bahwa kemampuan menulis laporan mahasiswa jurusan Teknik Kimia Politeknik Negeri Malang dapat ditingkatkan melalui pembelajaran berbasis portofolio.

Peningkatan kemampuan menulis laporan ini terjadi pada tahap persiapan menulis, tahap penulisan, dan tahap finalisasi. Peningkatan kemampuan menulis pada ketiga tahap tersebut dapat dilihat dari segi proses dan produk pembelajaran. Lebih lanjut hasil penelitian Puspita (2007), dengan kesimpulan bahwa melalui model pembelajaran berbasis portofolio, kemampuan siswa dalam menyampaikan materi di depan kelas dan belajar mandiri di rumah dapat ditingkatkan. Selain itu siswa menjadi lebih berani mengemukakan pendapat dan dapat menerapkan ilmu sejarah dalam kehidupan bermasyarakat.

Variasi penerapan model pembelajaran ini dapat juga menghindari kebosanan siswa dalam mengikuti pembelajaran. Penelitian Sinestesia (2006) yang berjudul "Improving students skills through "Portofolio" model of leraning processes: an experimental research at first students of SMA 8 Bengkulu in the academic year of 
2005/2006", menyimpulkan bahwa model pembelajaran portofolio dapat meningkatkan keterampilan menulis siswa. Penelitian Winarni (2007), menjelaskan bahawa penerapan metode pembelajaran berbasis portofolio lebih efektif daripada penerapan metode konvensional dalam meningkatkan hasil belajar siswa.

Model pembelajaran berbasis portofolio dapat meningkatkan hasil belajar siswa. Hal ini sejalan dengan hasil penelitian (Natalia, et al., 2017., Rambe \& Anggraini, 2014., Ipriadi \& Muhfahroyin, 2012) yang buktikan bahwa model pembelajaran berbasil portofolio dapat meningkatkan hasil belajar siswa. Sumarna at al., (2014) membuktikan terdapat perbedaan yang signifikan hasil belajar PKn antara siswa yang mengikuti model pembelajaran berbasis portofolio (portofolio based learning) dengan siswa yang mengikuti pembelajaran konvensional kelas V SD Gugus 4 Mengwi.

\section{SIMPULAN}

Berdasarkan hasil penelitian dan pemabahasan, maka dalam penelitian ini dapat disimpulkan, model pembelajaran berbasis portofolio cukup akurat untuk dilaksanakan dalam meningkatkan hasil belajar siswa. 


\section{DAFTAR PUSTAKA}

Arikunto, S. (2014). Prosedur Penelitian Suatu Pendekatan Praktik. Jakarta : Rineka Cipta.

Budimansyah D.(2003). Model Pembelajaran Portofolio. Bandung: PT. Genesindo

Fajar A. (2002). Portofolio dalam Pembelajaran. Bandung. PT. Remaja Rosdakarya

Ipriadi \& Muhfahroyin. (2012).Pembelajaran Berbasis Portofolio Untuk Meningkatkan Aktivitas Dan Hasil Belajar Biologi Siswa Kelas X Ma Negeri 2 Metro Semester Genap Tahun Pelajaran 2011/2012. FKIP. Universitas Muhammadiyah Metro.

Kunandar. (2013). Penilaian Authentik (Penilaian Hasil Belajar Peserta Didik Berdasarkan Kurikulum 2013). Jakarta: Rajawali Pers.

Mujianto. (2008). Peningkatan Kemampuan Menulis Laporan Melalui Pembelajaran Berbasis Portofolio. Malang : Politeknik Negeri Malang.

Natalia A., Saneba B., \& Hasdin. (2017). Penerapan Pembelajaran Berbasis Portofolio Untuk Meningkatkan Hasil Belajar IPS Siswa Kelas IV SD Inpres 1 Slametharjo Kabupaten Banggai. Jurnal Kreatif Tadulako Online. 5(1) 31-42

Puspita A.R. (2007).Peningkatan Prestasi Belajar IPS Sejarah melalui Model Pembelajaran Berbasis Portofolio pada Siswa Kelas VIII SMP Negeri 1 Doro Kabupaten Pekalongan Tahun Pelajaran 2006 / 2007. (Thesis) Semarang : Iniversitas Negeri Semarang.

Rambe A., \& Anggraini Y. (2014). Penerapan Model Pembelajaran Berbasis Portofolio Untuk Meningkatkan Hasil Belajar Menggambar Busana Di Smk Negeri 8 Medan. Jurnal Tabularasa Pps Unimed. 11(1) 1-15

Senestesia Y. (2006). Improving Student Writing Skill Through "Portofoli" Model Learning Processes: An Experimental Research at First Year Students Of SMAN 8 Bengkulu. (Thesis) Bengkulu : Unib

Sumarna A., Suniasih N., \& Wiyasa I. (2014). Pengaruh Model Pembelajaran Berbasis Portofolio Terhadap Hasil Belajar Pkn Siswa Kelas V Sd Gugus 4 Mengwi Badung. Jurnal Mimbar PGSD Universitas Pendidikan Ganesha Jurusan PGSD. 2(1)

Tukiran. (2008). Hubungan Model Pembelajaran Dengan Hasil Pembelajaran. Purwokerto : Unmuh. Purwokerto. 
Winarni A. (2007). Efektivitas Penerapan Metode Pembelajaran Berbasis Portofolio dalam Meningkatkan Hasil Belajar Siswa Mata Pelajaran Ekonomi Pokok Bahasan Kebijakan Pemerintah dalam Bidang Ekonomi Kelas X Semester II di SMA Negeri I Jekulo Kabupaten Kudus Tahun Pelajaran 2006/2007. (Thesis) Semarang: Universitas Negeri Semarang.

Zuhri, S. (2008). Pembelajaran Model Portofolio Pada Mata Pelajaran Agama Islam Di SMA “Al_Husien Salam" Kabupaten Magelang. (Thesis) Yogyakarta: PPS UII. 